\title{
4 Open Learning Tutorials
}

You are expected to provide appropriate tutorial contact for students. The functions of open learning tutorials are very much the same as for any tutorial and include:

* the provision of technical help with study difficulties;

* guidance on how to study;

* an indication of progress;

* Social contact, and confirmation of acceptance and belonging;

* maintenance of morale.

When tutors are not themselves providing lectures or seminar input, they can fall into the trap of repeating information already covered in the learning materials. This should, of course, be avoided. Tutorials provide an opportunity for students to express themselves and to deal with personal issues.

Tutorials should be planned to diagnose the students' needs, or meet needs that have been identified. A number of possible starting points for tutorials include:

* review the student's progress with the Workbook activities;

* discuss the draft outline of a Tutor Review Exercise;

* give written feedback on an exercise and discuss;

* look ahead at major Self Check Exercises;

* review the student's organisation of study and deadlines;

* discuss how what the students are learning relates to their work or life generally.

Such themes as these will allow opportunity for other matters to emerge and to be clarified. 